\title{
CdS Thin Film Transistor for Inverter and Operational Amplifier Circuit Applications
}

\author{
W. Wondmagegn ${ }^{\text {a }}$ I. Mejia ${ }^{c}$, A. Salas-Villasenor ${ }^{c}$, H. J. Stiegler ${ }^{c}$, M. A. Quevedo-Lopez ${ }^{c}$, R. J. \\ Pieper $^{\text {b }}$, and B. E. Gnade ${ }^{\mathrm{c}}$ \\ a Department of Physics and Engineering, Frostburg State University, Frostburg MD 21532, \\ USA, Phone: (301)687-7072, Fax: (301)687-7966, E-mail: wwondmagegn@frostburg.edu \\ ${ }^{\mathrm{b}}$ Department of Electrical Engineering, University of Texas at Tyler, Tyler TX 75799, USA, \\ ${ }^{c}$ Department of Materials Science and Engineering, University of Texas at Dallas \\ Richardson, TX 75080, USA
}

\begin{abstract}
Organic and inorganic Thin Film Transistors (TFTs) are fabricated, simulated, and tested for circuit applications. The devices are based on polycrystalline cadmium sulfide (CdS) and pentacene thin films. Both devices are simulated and analyzed using two-dimensional finite element simulation methodology. For $\mathrm{CdS}$, grain boundary and uniform trap distribution approaches are implemented. It is assumed that traps due to grain boundaries are uniformly distributed throughout the film. For pentacene a Poole-Frenkel mobility model is employed. After matching device simulation with experimental data, the SPICE model parameters are extracted for circuit simulation. The devices are tested for both analog and digital circuits. Operational Amplifier (OPAMP) and inverter circuits are tested. Two OPAMP topologies are compared and the results are discussed. One of the topologies is based on all n-type transistors using CdS TFT and the other topology is the two-stage Miller compensated CMOS design based on CdS and pentacene TFTs. The operational amplifiers have an open-loop voltage gain of 25.9 $\mathrm{dB}$ and $29.7 \mathrm{~dB}$ respectively. The performance of the CMOS design is found to be limited by performance of pentacene transistor.
\end{abstract}

Keywords:Thin Film Transistor; polycrystalline CdS; pentacene; TFT Operational Amplifier; drift diffusion; simulation; Gaussian distribution; field effect mobility

\section{Introduction}

Flexible electronics relies on Thin Film Transistors. Conventionally, Thin Film Transistors are formed from amorphous silicon (a-Si) thin film active materials. Recently TFTs have been fabricated using polycrystalline silicon (poly-Si) and implemented for different applications [1]. Polysilicon TFTs are used in active-matrix displays [2], static random-access memories [3], and electrically erasable programmable read-only memories [4]. The first thin film transistor, as it is structured today, was demonstrated by P.K Weimer in 1962. Weimer used a top gate staggered structure with a microcrystalline $\mathrm{CdS}$ active layer [5] and demonstrated a thin film transistor. $\mathrm{CdS}$ transistors are experimentally demonstrated since then [6-9]. Depending on the measurement temperature, the experimental data of CdS TFTs have been analyzed either on the 
basis of Mott's variable range hopping conduction process or thermionic emission of the carriers over the grain boundaries [6]. Because of its sulphur vacancy density, which is much higher than cadmium vacancy density, pure vapor-grown CdS tends to be n-type [10]. Similarly thin film transistors based on amorphous and polycrystalline silicon tend to be n-type transistors.

However analog and digital circuits based on Complementary-Metal-Oxide-Semiconductor (CMOS) circuit configuration require efficient n-type and p-type TFTs. Organic semiconductors are the main choices for p-type TFT applications, which offer the advantages of flexibility and compatibility with low temperature process and low-cost plastic substrates [11]. Organic electronics has been an area of extensive research and significant progress has been made in improving the quality and understanding of the operation of organic Thin Film Transistors $[12,13]$. Low-temperature hybrid CMOS circuits based on CdS and Pentacene TFTs have been demonstrated [14]. However this technology is hampered by the low mobility and low reliability of these devices. Recently, encouraging results are reported on fabricating TFTs with high field effect mobility. Organic thin film transistors with hole mobility as high as $43 \mathrm{~cm}^{2} / \mathrm{V}$-s are demonstrated [15].

Since transistors based on organic thin films tend to be p-type, development of n-type transistors from other materials compatible with low temperature process is needed. Having this in mind, significant research activity is underway by the research community to fabricate an efficient ntype thin film transistor based on inorganic and hybrid thin films [16-19]. This paper presents a work which is part of this effort. CdS transistor has been tested for both analog and digital circuits. OPAMP and inverter circuits based on CdS and pentacene thin film transistors are tested. Two OPAMP topologies are compared and the results are discussed. One of the topologies is based on all n-type transistors [20] using CdS TFT and the other topology is the two-stage Miller compensated CMOS design [21] based on CdS and pentacene TFTs.

\section{Experiment}

2.1 CdS TFT - TFTs are fabricated on $500 \mathrm{~nm} \mathrm{SiO}_{2}$ to isolate the substrate from the rest of the structure in a bottom gate contact configuration. The structure starts with $100 \mathrm{~nm}$ of $\mathrm{Cr}$ deposited using e-beam thermal evaporation and subsequently patterned to define the gate contact. Then, $90 \mathrm{~nm}$ of $\mathrm{HfO}_{2}$ is deposited using atomic layer deposition (ALD) at $100^{\circ} \mathrm{C}$ to serve as gate dielectric. After the gate dielectric formation, the substrates were immersed in a chemical bath using an ammonia-free solution to deposit $70 \mathrm{~nm} \mathrm{CdS}$ films at $70^{\circ} \mathrm{C}$ on top of the $\mathrm{HfO}_{2}$ [22]. Afterwards, $500 \mathrm{~nm}$ of parylene-C was deposited immediately on top of $\mathrm{CdS}$ to act as a protective film to prevent any of the chemicals commonly used in photolithography touching the CdS. Parylene-C was then patterned using $\mathrm{O}_{2}$ plasma. Both $\mathrm{CdS}$ and $\mathrm{HfO}_{2}$ films were patterned and then etched using clorhidric acid $(\mathrm{HCl}) /$ water and buffered oxide etch (BOE), respectively. The next step is the deposition and patterning of $100 \mathrm{~nm}$ of $\mathrm{Al}$ to form the source and drain contacts. Finally, the samples were annealed at $300^{\circ} \mathrm{C}$ in forming gas for one hour to remove the excess of oxygen in the $\mathrm{CdS}$ and to improve the contact between $\mathrm{CdS}$ and $\mathrm{Al}$.

2.2 Pentacene TFT - Using a process previously reported by our group [23,24], bottom contact devices are fabricated on silicon nitride $\left(\mathrm{Si}_{3} \mathrm{~N}_{4}\right)$ deposited on silicon wafers. Chromium $(50 \mathrm{~nm})$ was deposited by e-beam evaporation and then lithographically patterned and wet etched to form the gate electrode. Parylene was deposited by chemical vapor deposition (CVD) at room 
temperature as the gate insulator. Contact vias to the bottom electrode were photolithographically patterned and etched using oxygen reactive ion etching (RIE). Au contacts were deposited by e-beam evaporation, and then photolithographically patterned and wet etched to form source, drain and gate electrode (through via) contacts. After top contact definition, pentacene was thermally evaporated with the substrate held at room temperature, at a pressure < $5 \times 10^{-7}$ Torr during evaporation with a deposition rate of $0.5 \AA / \mathrm{sec}$. Performance of the resulting devices was evaluated using DC electrical characteristics of the pentacene TFTs determined using a Keithley 4200 semiconductor characterization system

\section{Device Simulation}

3.1 CdS TFT - In comparison to a conventional single-crystal metal-oxide-semiconductor field effect transistor, the transport mechanism in a polycrystalline material thin-film transistor (TFT) is complicated [2]. The complication comes from the existence of discrete grain boundaries in the channel region. To understand this phenomenon, a number of empirical [25-27] and physical [28-31] models have been proposed particularly for the transport mechanism in a polysilicon TFT. These physical models are generally formulated either by assuming a uniform distribution of traps in the channel [28,29] or localized traps at the grain boundaries that separate pure single crystal grains $[30,31]$. In the case of small grain size and high trap density polysilicon material, the assumption of uniform trap distribution over the entire volume of the film is acceptable. However, this assumption fails to give reliable results for polysilicon TFTs with large grain sizes. The assumption of localized traps at the grain boundaries better handles the channels with larger grain size and less traps [32,33]. In the present work, both grain boundary and uniform trap distribution schemes are tested for comparison.

Device characteristics of $\mathrm{CdS}$ field effect transistors are carried out using the drift-diffusion model. The two-dimensional device simulation is performed using Silvaco's "ATLAS" device simulator [34]. The device (see Fig. 1) is designed with $80 \mu \mathrm{m}$ channel length and width. A driftdiffusion (DD) simulation model was used in which the basic equations taken are similar to those used for a single-crystal device except that traps and defects are included in the model. The polycrystalline material is composed of crystallites or grains separated by grain boundaries [35].

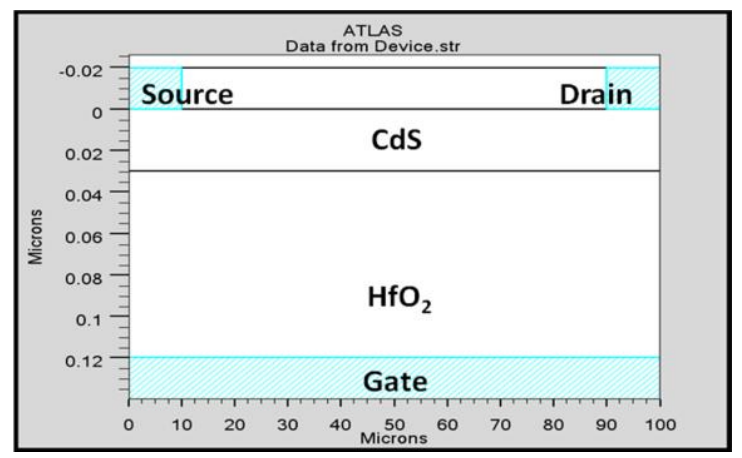

Fig.1 Simulated CdS Thin Film Transistor

The grain boundary consists of a few atomic layers of disordered atoms that result in a large number of defects, which limits the carrier mobility of the material. The charge carrier mobility 
of polycrystalline material is an order of magnitude smaller than that of the single crystal and it strongly depends on the size of crystallites and deposition condition. The mobility in such materials also has a direct proportionality with temperature [36] as opposed to inverse proportionality between the mobility and temperature in single crystalline material [35]. Based on the work of Orouji et al. [37], for polysilicon, Caughey-Thomas mobility model, as given in the following equations, is used [38].

$$
\begin{aligned}
& \mu_{n}(\odot)=\mu_{n 0}\left[1+\left(\frac{\mu_{n 0} \odot}{V_{s a t}^{n}}\right)^{\beta_{n}}\right]^{-1 / \beta_{n}} \\
& \mu_{p}(\odot)=\mu_{p 0}\left[1+\left(\frac{\mu_{p 0} \odot}{V_{s a t}^{p}}\right)^{\beta_{p}}\right]^{-1 / \beta_{p}}
\end{aligned}
$$

where $\varepsilon$ is the parallel electric field and $\mu_{\mathrm{n} 0}$ and $\mu_{\mathrm{p} 0}$ are the low field electron and hole mobilities respectively. $\beta_{\mathrm{n}}$ and $\beta_{\mathrm{p}}$ are user definable model parameters. $V^{n}{ }_{\text {sat }}$ and $V^{p}{ }_{\text {sat }}$ are saturation velocities of electrons and holes respectively. The model takes into account velocity saturation and depends on the electric field in the direction of current flow. Saturation velocity of $10^{7} \mathrm{~cm} / \mathrm{s}$ and constant low field mobility of $4.3 \mathrm{~cm}^{2} / \mathrm{V}-\mathrm{s}$ are used. This is consistent with the low grain size of the CdS sample used in this work $(50 \mathrm{~nm})$. Depending on the grain size, mobilities ranging from 0.1 to $150 \mathrm{~cm}^{2} / \mathrm{Vs}$ have been reported for CdS [8]. The work function of $4.1 \mathrm{eV}$ for aluminum source/drain electrodes and relative permittivity of 17 for $\mathrm{HfO}_{2}$ dielectric are used $[39,40]$. Chromium with workfunction of 4.37 [41] was used as gate electrode. Semiconductorinsulator interface charge in the order of $10^{11} \mathrm{q} \mathrm{cm}^{-2}$, where $q=1.6 \times 10^{-19} \mathrm{C}$, has been used in the simulation. It gives good agreement between threshold voltages extracted from experiment and simulation. The threshold voltage, which is extracted from the intercept of the maximum slope of the plot of $\sqrt{I_{D S}}$ verses $V_{G S}$ of the transistor, is approximately $5 \mathrm{~V}$. CdS Material parameters collected from literature [42-44] and used in the simulation are summarized in Table 1.

\begin{tabular}{|lll|}
\hline Material & Parameter & Values \\
\hline CdS (active material) & Band-gap & $2.42 \mathrm{eV} \mathrm{[42]}$ \\
& Electron affinity & $4.0 \mathrm{eV} \mathrm{[43]}$ \\
& Electron low field mobility & $4.3 \mathrm{~cm}^{2} / \mathrm{V}-\mathrm{s}$ \\
& Hole low field mobility & $0.3 \mathrm{~cm}^{2} / \mathrm{V}-\mathrm{s}$ \\
& Thomas Claughey beta parameters & $\beta_{p}=1 \beta_{n}=2$ \\
& Relative permittivity & $8.9[42]$ \\
& Donor doping & $10^{16} \mathrm{~cm}^{-3}[44]$ \\
& Density of states & $10^{21} \mathrm{~cm}^{-3}$ \\
\hline HfO $_{2}$ (dielectric) & Relative permittivity & 17 \\
\hline CdS/HfO & Interface charge (number density) & $10^{11} \mathrm{~cm}^{-2}[39]$ \\
\hline Al $(\mathbf{S}$, D contacts) & Workfunction & $4.1 \mathrm{eV} \mathrm{[40]}$ \\
Cr (G contact) & Work function & $4 . .37 \mathrm{eV} \mathrm{[41]}$ \\
\hline
\end{tabular}

Table 1 Summary of material parameters used in both simulation approaches 


\subsubsection{Uniform trap distribution modeling}

In this simulation approach, it is assumed that traps due to grain boundaries are uniformly distributed throughout the film. Both exponential and Gaussian trap distributions are introduced in the simulation. For an exponential tail distribution (Equations 3 and 4), the trap density is described by its conduction and valence band edge intercept densities $\left(\mathrm{n}_{\mathrm{TA}}\right.$ and $\mathrm{n}_{\mathrm{TD}}$ ), and by its characteristic decay energy ( $\mathrm{w}_{\mathrm{TA}}$ and $\left.\mathrm{w}_{\mathrm{TD}}\right)$.

$$
\begin{aligned}
& g_{T A}(E)=n_{T A} \exp \left[\frac{E-E_{C}}{w_{T A}}\right] \\
& g_{T D}(E)=n_{T D} \exp \left[\frac{E_{V}-E}{w_{T D}}\right]
\end{aligned}
$$

where the expressions above are defined for $E_{V} \leq E \leq E_{C}$. The Gaussian distribution is described by its density of states $\left(\mathrm{n}_{\mathrm{GA}}\right.$ and $\mathrm{n}_{\mathrm{GD}}$ ), its characteristic decay energy ( $\mathrm{w}_{\mathrm{GA}}$ and $\mathrm{w}_{\mathrm{GD}}$ ), and its peak energy/peak distribution $\left(\mathrm{E}_{\mathrm{GA}}\right.$ and $\mathrm{E}_{\mathrm{GD}}$ ) as shown in equations 5 and 6 . The values of the simulation parameters are listed in Table 2 .

$$
g_{G A}(E)=n_{G A} \exp \left[-\left(\frac{E_{G A}-E}{w_{G A}}\right)^{2}\right]
$$

\begin{tabular}{|l|l|}
\hline Parameter & value \\
\hline $\mathrm{n}_{\mathrm{TA}}$ & $10^{19} \mathrm{~cm}^{-3} \mathrm{eV}^{-1}$ \\
$\mathrm{n}_{\mathrm{TD}}$ & $10^{19} \mathrm{~cm}^{-3} \mathrm{eV}^{-1}$ \\
$\mathrm{n}_{\mathrm{GA}}$ & $1.5 \times 10^{18} \mathrm{~cm}^{-3} \mathrm{eV}^{-1}$ \\
$\mathrm{n}_{\mathrm{GD}}$ & $1.5 \times 10^{17} \mathrm{~cm}^{-3} \mathrm{eV}^{-1}$ \\
$\mathrm{w}_{\mathrm{TA}}$ & $0.1 \mathrm{eV}$ \\
$\mathrm{w}_{\mathrm{TD}}$ & $0.1 \mathrm{eV}$ \\
$\mathrm{w}_{\mathrm{GA}}$ & $0.4 \mathrm{eV}$ \\
$\mathrm{w}_{\mathrm{GD}}$ & $0.4 \mathrm{eV}$ \\
$\mathrm{E}_{\mathrm{GA}}$ & $0.6 \mathrm{eV}$ \\
$\mathrm{E}_{\mathrm{GD}}$ & $0.6 \mathrm{eV}$ \\
\hline
\end{tabular}

Table 2 Summary of parameters for exponential and Gaussian trap states

$$
g_{G D}(E)=n_{G D} \exp \left[-\left(\frac{E-E_{G D}}{w_{G D}}\right)^{2}\right]
$$

Previously, CdS is reported to have equivalent uniform distribution of electron traps in the range of $7 \times 10^{14}$ to $5 \times 10^{18} \mathrm{~cm}^{-3} \mathrm{eV}^{-1}$ in a wide range of trap energies [45]. As implemented in this work the traps could be well represented by the combination of a Gaussian and exponential distributions. Acceptor and donor trap energy levels are measured with respect to the conduction and valence bands, respectively as shown in Fig. 2. Specifically, as seen in Fig. 2, $E_{G}$ is the band gap, $E_{t A}$ is acceptor trap level, $E_{t D}$ is donor trap level, $E_{F}$ is the Fermi level, $E_{C}$ is the conduction band edge, and $E_{V}$ is the valence band edge. 


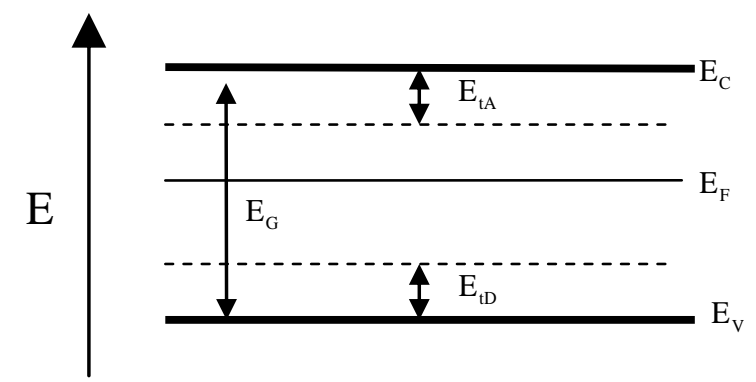

Fig.2 Representation of acceptor and donor trap energy levels [44]

\subsubsection{Multiple grain boundary modeling}

Based on the two dimensional finite element analysis, grain boundaries are treated as two-dimensional interfaces where a large amount of donor and acceptor states can be accommodated. The charge trapped in these states influences the electric potential distribution via Poisson's equation; carrier transport occurs according to the drift-diffusion mechanism [46]. The grain boundary is modeled by considering grain boundaries within the channel of the transistor, which are perpendicular to the direction of current flow (see Figure 3). Recent experimental investigations demonstrated the effect of grain boundaries, which are perpendicular and parallel to the direction of current flow, on the device performance $[32,47]$. In those studies, it has been demonstrated that grain boundaries parallel to the current direction have smaller impact on the current flow, but they can increase leakage current [47]. In contrast, grain boundaries perpendicular to the current direction lead to more degradation of the device performance. The simulation grain size along the channel is taken as $1 \mu \mathrm{m}$, which is approximately 20 times higher than average measured grain size in actual device $(50 \mathrm{~nm})$. Efforts to simulate with the same grain size as the physical device were limited by requirements for an excessive number of finite element nodes. The corresponding computation time is also excessive. Prior work in the literature, in the area of polycrystalline silicon, indicates simulations would be possible with as little as one grain boundary taken along FET channel [48].

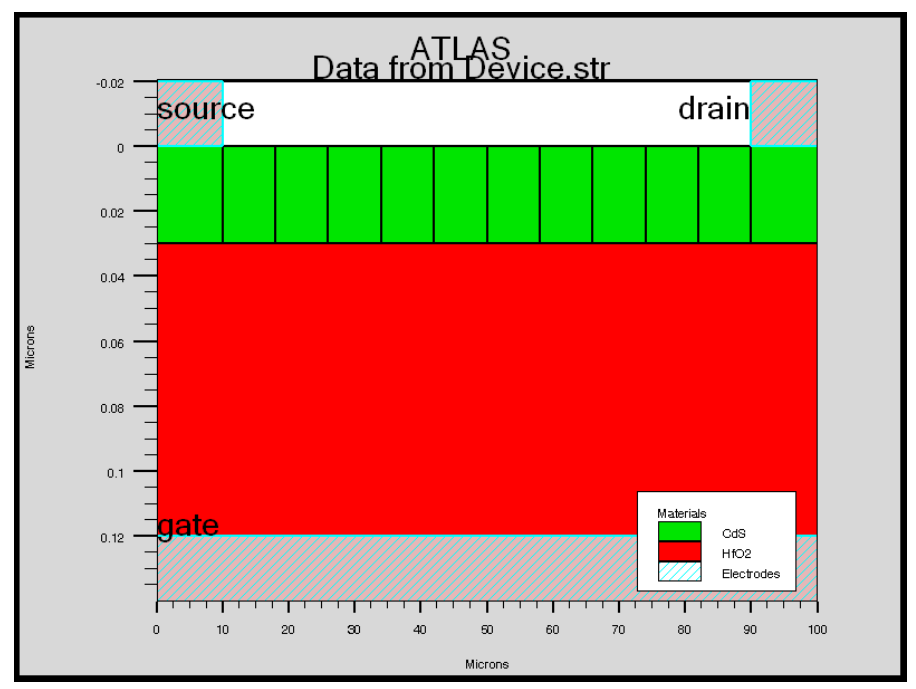

Fig.3 Channel divided in to multiple grains 
The transport across the grain boundary is modeled by the interface traps and thermionic emission across the grain boundary due to the potential barrier resulted from the trapped charges [2]. An order of $10^{11} \mathrm{~cm}^{-2}$ interface traps are used at grain boundaries with discrete energy levels ranging from 0.1 to $0.6 \mathrm{eV}$ in intervals of $0.1 \mathrm{eV}$. The energy levels are measured relative to the conduction and valence bands as shown in Figure 2. Details of trap states are given in Table 3. Previous experimental results indicated a typical density of $7 \times 10^{11} \mathrm{~cm}^{-2}$ interface traps at grain boundaries of CdS polycrystalline semiconductor [49]. The potential barrier height resulted from the traps at grain boundaries are extracted from the simulation and presented in Figure 4. As shown in the figure, the traps creates about $50 \mathrm{mV}$ potential barrier at grain boundaries, which is in the same order as reported in literature [50].

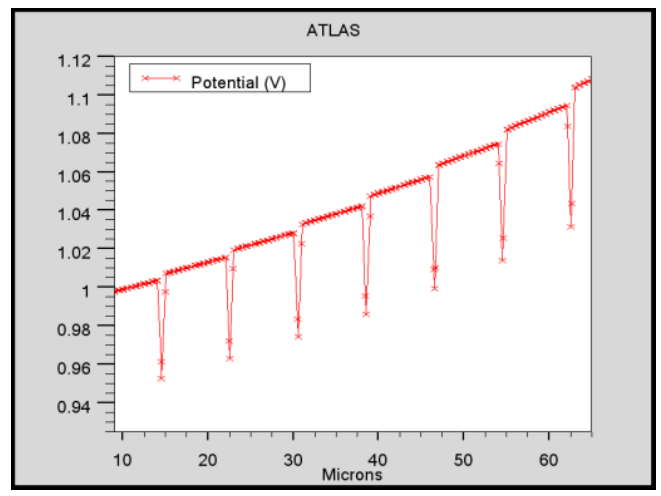

Fig.4 Potential barrier at grain boundaries created by interface traps

\begin{tabular}{|llll|}
\hline Type & $\begin{array}{l}\text { Energy } \\
\text { level }(\mathrm{eV})\end{array}$ & Density $\left(\mathrm{cm}^{-2}\right)$ & Life time $(\mathrm{ns})$ \\
\hline Acceptor & 0.1 & $8 \times 10^{11}$ & 1 \\
& 0.2 & $7 \times 10^{11}$ & 1 \\
& 0.3 & $5 \times 10^{11}$ & 1 \\
& 0.4 & $5 \times 10^{11}$ & 1 \\
& 0.5 & $3 \times 10^{11}$ & 10 \\
& 0.6 & $1 \times 10^{11}$ & 10 \\
& 0.7 & $7 \times 10^{10}$ & 10 \\
& 0.8 & $1 \times 10^{10}$ & 100 \\
\hline Donor & 0.6 & $10^{10}$ & 1000 \\
& 0.7 & $10^{10}$ & 1000 \\
& 0.8 & $10^{10}$ & 1000 \\
\hline
\end{tabular}

Table 3 Summary of parameters for exponential and Gaussian trap states

3.2 Pentacene TFT - The transistor studied in this paper has W/L of $641 / 6 \mu \mathrm{m}$, with $150 \mathrm{~nm}$ pentacene as the active material, and $150 \mathrm{~nm}$ parylene as the gate dielectric. The simulation is performed using Silvaco's atlas device simulator [34]. A Poole-Frenkel mobility model (eq. 7) for pentacene active channel is employed. Poole-Frenkel conduction is due to field-enhanced thermal excitation of trapped charge carriers [34,51]. According to this transport model, the field 
assisted delocalization of trapped charge carriers will result a large increase in the drain current of the device [52-54].

$$
\begin{array}{r}
\mu(E)=\mu(0) \exp \left(\frac{\beta \sqrt{E}}{k T}\right) \\
\text { and } \mu(0)=\mu_{i} \exp \left(-\frac{\Delta}{k T}\right)
\end{array}
$$

where $\mu(E)$ is the field dependent mobility, $E$ is the electric field, $\beta$ is the Poole-Frenkel factor, $\mu_{\mathrm{i}}$ is the intrinsic mobility, and $\Delta$ is the zero field thermal activation energy. The simulation details of pentacene field effect transistor is presented in our previous work [55]

\section{Results and Discussion}

\section{(i) Device simulation}

From transmission electron microscopy (TEM) studies, the CdS sample used in this work has a grain size of about $50 \mathrm{~nm}$, which is at the low end of reported values [10]. The grain size is also very small compared to the channel length of the simulated device. Considering this, the proposed premise, already demonstrated for polysilicon [28,29], is that the electrical impact of grain boundaries in a $\mathrm{CdS}$ thin film transistors could be captured with a model which removes the actual grain boundaries and substitutes uniform distributions of exponential and Gaussian trap states throughout the channel. Figure 5 (a) shows the characteristic family of curves of $\mathrm{CdS}$ TFT for gate voltages 5, 10, and 15 volts. Figure 5 (b) shows transfer curves for experiment and simulations. In the figures, the black curve represents experimental data, the red represents the simulation with uniform distribution of traps and the green represents simulation with multiple grains and grain boundaries in the channel. A comparison of experimental data with simulation results shows that both types of simulation methodologies gave comparable results with approximately the same level of agreement with experiment. Particularly, for higher gate voltages the simulations seem to overlap on each other indicating this example provides support for the above mentioned premise, i.e. uniform distributions of Gaussian and exponential traps could be used to approximate the multi-grain structure of polycrystalline $\mathrm{CdS}$ material in the channel.

The fabricated and simulated CdS device has field-effect mobility of $4.29 \mathrm{~cm}^{2} / \mathrm{V}$-s. The maximum switching frequency at which a transistor circuit can operate is calculated using Equation 9 [56]. Using $20 \mathrm{~V}$ drain voltage and $80 \mu \mathrm{m}$ channel length, the calculated frequency is 1.34 MHz. This is comparable to the speed reported for flexible thin film transistors [56]. However, in comparison silicon based transistors have speeds in gigahertz. Clearly TFTs should be aimed for low cost and low end products.

$$
f_{M A X} \approx \frac{\mu V_{D S}}{L^{2}}
$$




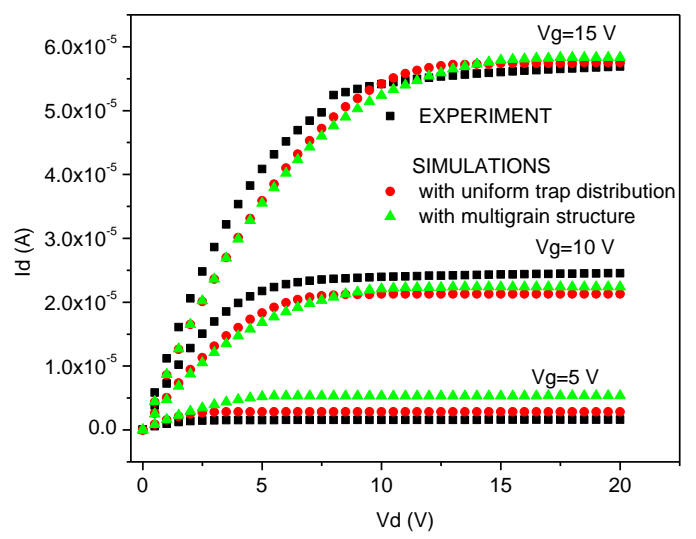

(a)

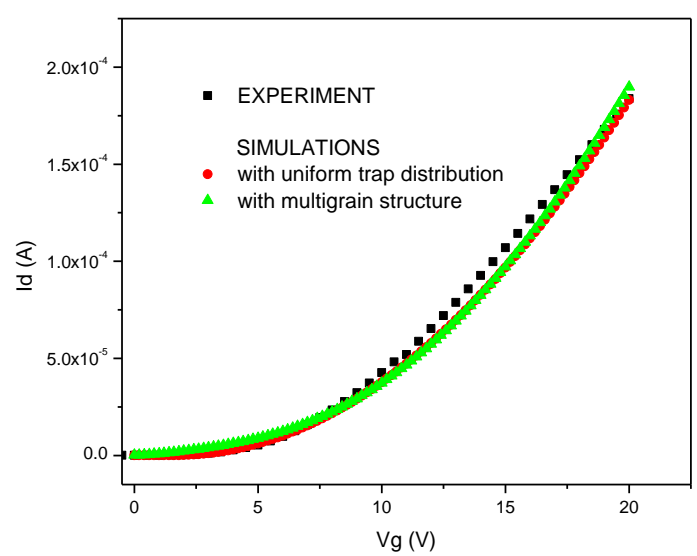

(b)

Fig.5 (a) Id-Vd curves and (b) Transfer curves for experiment (black squares), simulations with Gaussian density of states (red circles), and simulation with channel containing grains and grain boundaries (green triangles).

\section{(ii) Circuit simulation}

a. Inverter - Based on device simulation results presented above, the uniform distribution of traps methodology was implemented for an inverter simulation. The inverter was simulated with a device and circuit level mixed mode simulation. Mixed mode simulation accepts both physical level representation and SPICE level representation of devices. It helps to study critical devices in a circuit by representing them as a physical device as opposed to using their SPICE model parameter. Fig. 6 (a) shows the simulated inverter schematic. The top transistor, in diode connected form, serves as the load resistor in the inverter circuit. It has channel width of $400 \mu \mathrm{m}$ and channel length of $20 \mu \mathrm{m}$. The bottom transistor is the switching transistor with a transient input attached to its gate terminal. Its dimension is $40 \mu \mathrm{m}$ by $20 \mu \mathrm{m}$. The two transistors are defined as a physical $\mathrm{CdS}$ transistor with material and model parameters listed in Tables 1 and 2. Fig. 6 (b) shows the transfer characteristics (Vout vs. Vin) for both simulation and experiment. The graph shows a well-defined steplike transfer curve with steep slope, indicating a high gain in the transition region. The inverter has a nearly full rail-to-rail swing. The output HIGH and output LOW are the same voltage as $\mathrm{V}_{\mathrm{DD}}$ and ground, respectively. Measured with respect to ground (GND), the maximum input voltage is +20 volts the same as $V_{D D}$ on the diagram.

As shown in the figure the simulation shows a good match with experimental data obtained from measurements made on $\mathrm{CdS}$ transistor inverter fabricated with process 
described above. The simulation suggested a slight difference in interface charge between the load and switching transistors, which brings about a difference between their threshold voltages. The best match was obtained with $3 \times 10^{11} \mathrm{~cm}^{-2}$ and $1 \times 10^{12}$ $\mathrm{cm}^{-2}$ interface charges for the switching and load transistors respectively.

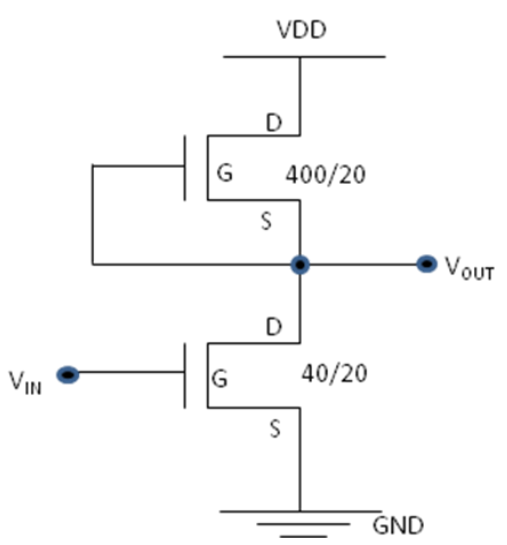

(a)

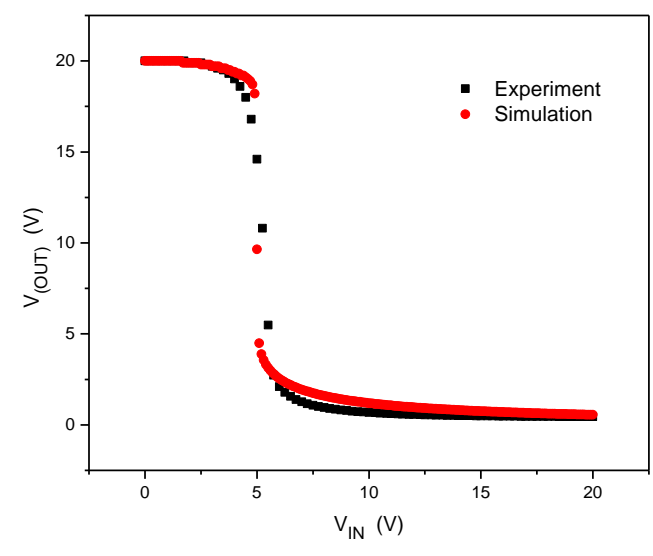

(b)

Fig.6 (a) Inverter schematic based on CdS TFT with the transistor channel width to length ratio W/L mentioned on the figure and (b) simulation Input-Output characteristics of the inverter.

b. OPAMPS - After matching device simulation with experimental data, the SPICE parameters of the devices are extracted using UTMOST III software. For CdS devices the RPI's Amorphous TFT model [57] is used whereas for pentacene transistors the poly-crystalline TFT model is used. Using these SPICE parameters, circuit schematics of two OPAMP topologies, as shown in Figures 7(a) and 8(a), were built in SmartSpice. The design parameters for each topology are given in Tables 4 and 5. The circuits are then simulated and their Bode plots are given in Figures 7(b) and 8(b). The OPAMP simulation results for all ntype topology and the Miller-compensated topology are given in Tables 6 and 7 respectively. As shown in the tables the Miller-compensated configuration has a higher performance (29.7 $\mathrm{dB}$ gain and $604 \mathrm{~Hz}$ cutoff) than that of the all n-type configuration ( $25.9 \mathrm{~dB}$ gain and 188.8 $\mathrm{Hz}$ cutoff). The performance of the simulated operational amplifiers is in the range of reported values for TFT based operational amplifiers. Open loop voltage gains in the range of $18-50 \mathrm{~dB}$ have been reported previously [58-61]. Obviously, the performance of the tested operational amplifier circuits is far below the performance of the state of art devices based on silicon. Typical general purpose 741 OPAMP family has open-loop gain in the order of 106 $\mathrm{dB}$ and cutoff frequency in the order of $10 \mathrm{~Hz}$ [21]. However such a high performance is not expected from Thin Film Transistor technologies. These new technologies are not supposed to replace Silicon Integrated Circuits (ICs) in high performance computational applications [62]. Due to their flexibility and low temperature process they have broad applications in areas such as display technology and sensor networks. 


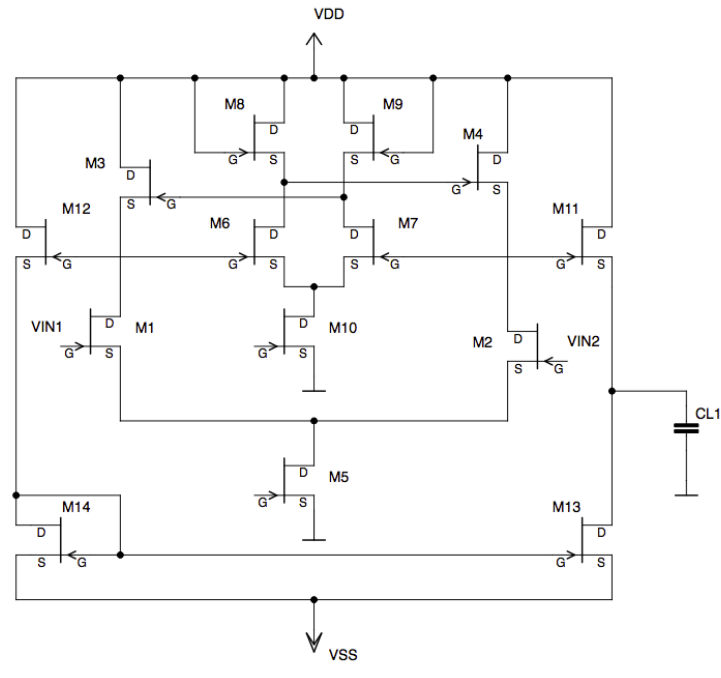

(a)

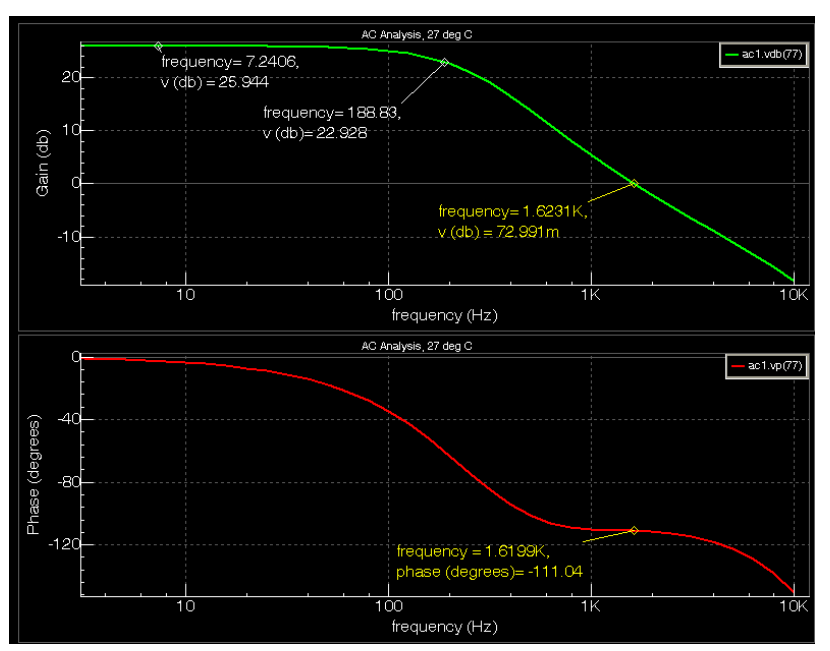

(b)

Fig.7 a) All n-type OPAPM topology b) gain and phase plots for the OPAMP

\begin{tabular}{|l|l|l|l|l|l|l|l|l|l|}
\hline $\mathrm{W} 1,2,6,7$ & W3,4 & W5 & W11-14 & W8,9 & W10 & L & CL & $\begin{array}{l}\text { VDD,VG_M10, } \\
\text { VG_M5 }\end{array}$ & VSS \\
\hline $160 \mu \mathrm{m}$ & $100 \mu \mathrm{m}$ & $280 \mu \mathrm{m}$ & $320 \mu \mathrm{m}$ & $120 \mu \mathrm{m}$ & $320 \mu \mathrm{m}$ & $20 \mu \mathrm{m}$ & $10 \mathrm{p}$ & $20 \mathrm{~V}$ & $-20 \mathrm{~V}$ \\
\hline
\end{tabular}

Table 4. Design parameters of all n-type OPAMP topology

\begin{tabular}{|l|l|l|l|l|}
\hline Gain $(\mathrm{V} / \mathrm{V})$ & Gain $(\mathrm{dB})$ & $\mathrm{f}_{3 \mathrm{db}}(\mathrm{Hz})$ & Unit gain freq. $(\mathrm{Hz})$ & Phase margin (degrees) \\
\hline 19.8 & 25.9 & 188.8 & $1.6 \mathrm{k}$ & 69 \\
\hline
\end{tabular}

Table 5. Performance parameters of all n-type OPAMP topology
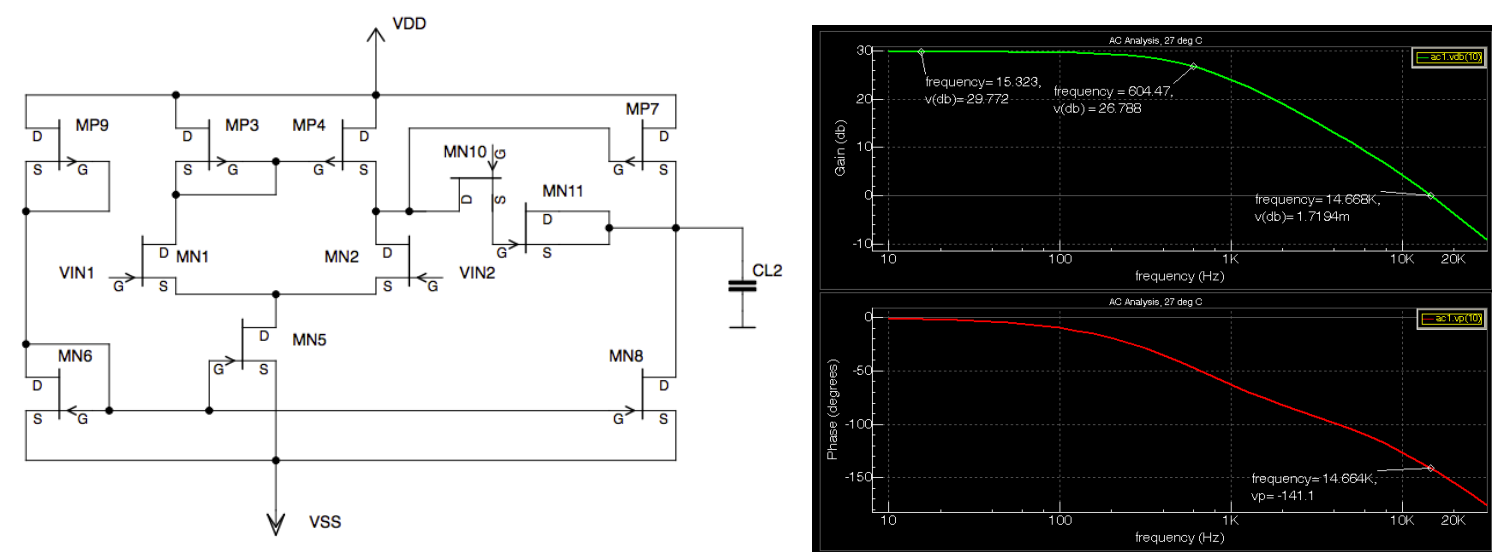
Fig. 8 a) Schematics of Miller-compensated OPAPM topology b) gain and phase plots for the OPAMP

\begin{tabular}{|l|l|l|l|l|l|l|}
\hline Wn1,2 & Wn5 & Wn6,8 & Wp3,4 & Wp7,9 & Ln & Lp \\
\hline $160 \mu \mathrm{m}$ & $280 \mu \mathrm{m}$ & $320 \mu \mathrm{m}$ & $1700 \mu \mathrm{m}$ & $3400 \mu \mathrm{m}$ & $20 \mu \mathrm{m}$ & $6 \mu \mathrm{m}$ \\
\hline \begin{tabular}{|l|l|l|l|l|l|}
\hline Mn10 & Mn11 & CL & VDD & VSS & VMg10 \\
\hline W=40 L=30 & W=160 L=20 & $10 \mathrm{p}$ & $20 \mathrm{~V}$ & $-20 \mathrm{~V}$ & $8 \mathrm{~V}$ \\
\hline
\end{tabular}
\end{tabular}

Table 6. Design parameters of Miller-compensated OPAMP, where $\mathrm{n}$ indicates $\mathrm{n}$-type transistor and $\mathrm{p}$ indicates p-type transistor

\begin{tabular}{|l|l|l|l|l|}
\hline Gain $(\mathrm{V} / \mathrm{V})$ & Gain $(\mathrm{dB})$ & $\mathrm{f}_{3 \mathrm{db}}(\mathrm{Hz})$ & Unit gain freq. $(\mathrm{Hz})$ & Phase margin (degrees) \\
\hline 30.8 & 29.7 & 604 & $14.6 \mathrm{k}$ & 39 \\
\hline
\end{tabular}

Table 7. Performance parameters of the Miller-compensated OPAMP topology

\section{Conclusion}

$\mathrm{CdS}$ thin film transistor was fabricated, simulated, and demonstrated in circuits with all n-type and CMOS type circuit topologies. Pentacene TFT is used as a complementary p-type device in CMOS topologies. Current vs. voltage characteristics simulations of field effect transistors based on $\mathrm{CdS}$ semiconductor are carried out using the drift-diffusion model. Two types of simulation methodologies, which were demonstrated for poly-silicon, are implemented for $\mathrm{CdS}$ polycrystalline materials. These are the uniform distribution of traps method and a method based on dividing the channel in to grain boundaries. Simulation results are compared with experiment and device parameters are extracted. Both types of simulations give good level of agreement with experiment. It is observed that the assumption of uniformly distributed traps in the channel well approximated the multi grain characteristics of $\mathrm{CdS}$ sample used in this study. Because the grain size of our CdS sample was small enough, about $50 \mathrm{~nm}$, the essential physics of such a TFT could be captured in a model represented by the Gaussian distribution density of trap states in a CdS channel. This methodology also gives simplicity and efficient simulation time compared to dividing the channel in to arbitrary number of grains, which requires a very large number of simulation nodes.

The devices are tested in inverter and OPAMP circuits. A mixed mode simulation of an inverter based on $\mathrm{CdS}$ thin film transistors was performed. The inverter simulation matches very well with experiment. OPAMPs of both all n-type topology and Miller-compensated topology are simulated and compared. The Miller-compensated configuration has a higher performance (30.8 V/V gain and $604 \mathrm{~Hz}$ cutoff) than that of the all n-type configuration $(19.8 \mathrm{~V} / \mathrm{V}$ gain and $188.8 \mathrm{~Hz}$ cutoff). However the dimensions of the p-type pentacene transistors are much higher than that of n-type CdS transistors. This is because of the low mobility performance characteristics of pentacene transistors compared to that of CdS TFTs. Therefore we conclude that the development of high performance p-type TFTs would be very important for the application of Miller compensated OPAMPs based on CdS n-type transistor 


\section{Acknowledgment}

We gratefully acknowledge the Department of Defense for supporting this work (Army Research Office Contract W911NF-07-2-0059).

\section{References}

1. Gan, F. Y., and Shih, I., IEEE Transactions on Electron Devices, 49, 15 (2002)

2. Chow, T., and Wong, M., IEEE Transactions on Electron Devices, 56, 1493 (2009)

3. Uemoto, Y., Fujii, E., Nakamura, A., and Senda, K., VLSI Symp. Tech. Dig., 21 (1990)

4. Sato, A., Momiyama, Y., Nara, Y., Sugii, T., Arimoto, Y., and Ito, T., IEEE Trans. Electron Devices, 40, 2126 (1993)

5. Weimer, P. K., Proceedings of the Institute of Radio Engineers, 50, 462 (1962)

6. Ebenezer, E., Murali, K. R., Chockalingam, M. J., Venkatesan, V. K., Journal of Materials Science, 23, 3861 (1988)

7. Seon, J.-B., Lee, S., Kim, J. M., Jeong, H.-D., Chem. Mater., 21, 604 (2009)

8. Miksic, M.G., Schling, E. S., and Haering, R. R., Solid-State Electronics Pergamon Press, 7, 39 (1964)

9. Schon, J. H., Schenker, O., Batlogg, B., Thin Solid Films, 385, 271(2001)

10. Garcia-Cuenca, M. V., Morenza, J. L., Bertran, E. and Lousa, A., J. Phys. D: Appl. Phys., 20, 958 (1987)

11. Voss, C., Subramanian, S., Chang, C.-H., J. Appl. Phys., 96, 5819 (2004)

12. Fabiano, S., Wang, H., Piliego, C., Jaye, C., Fischer, D. A., Chen, Z., Pignataro, B., Facchetti, A., Loo, Y.-L., and Loi, M. A., Adv. Funct. Mater., 21, 4479 (2011)

13. Kumar, B., Kaushik, B. K., Negi, Y. S., Goswami, V., Microelectronics Reliability, 54, 100 (2014)

14. Mejia, I., Salas-Villasenor, A. L., Avendano-Bolivar, A., Horvath, J., Stiegler, H., Gnade, B. E., and Quevedo-Lopez, M. A., IEEE Electron Device Letters, 32, 1086 (2011)

15. Yuan, Y., Giri, G., Ayzner, A. L., Zoombelt, A. P., Mannsfeld, S. C. B, Chen, J., Nordlund, D., Toney, M. F., Huang, J., Bao, Z., Nature Communications 5, No 3005, (2014)

16. Dey , A., Avendanno, A., Venugopal , S., Allee , D., Quevedo , M., and Gnade , B., IEEE Electron Device Letters, 32, No. 5, (2011)

17. Song, W., Kwon, S. Y., Myung, S., Jung, M. W., Kim, S. J., Min, B. K., Kang, M.-A, Kim, S. H., Lim, J., An, K.-S., Scientific Reports 4, No. 4064, (2014)

18. Mejia, I. Salas-Villasenor, A.L. ; Dongkyu Cha ; Alshareef, H.N. ; Gnade, B.E. ; Quevedo-Lopez, M.A., Electron Devices, IEEE Transactions on (Volume:60 , Issue: 1 (2013) $327-332$

19. Gan, F.Y., Shih, I., IEEE Transactions on Electron Devices, Vol. 49, 1 (2002) 15

20. Bae, B.-S., Choi, J.-W., Oh, J.-H., Jang, J., IEEE Trans. Electron Devices, vol. 53, (2006) 494

21. Salivahanan, Linear Integrated Circuits Paperback, Mcgraw Hill Higher Education (2007)

22. Salas-Villasenor, A. L., Mejia, I., Hovarth, J., Alshareef, H. N., Cha, D. K., RamirezBon, R., Gnade, B. E., and Quevedo-Lopez, M. A., Electrochem. Solid-State Lett., 13, H313 (2010) 
23. Gowrisanker, S., Quevedo-Lopez , M.A., Alshareef, H. N., Gnade, B., Venugopal, S., Krishna, R., Kaftanoglu, K., Allee, D., Organic Electronics 10, 1217 (2009)

24. Gowrisanker, S., Ai, Y., Jia, H., Quevedo-Lopez, M. A., Alshareef, H. N., Trachtenberg, I., Stiegler, H., Edwards, H., Barnett, R., and Gnade, B. E., Electrochemical and SolidState Letters, 12(3) H50-H53 (2009).

25. Serikawa, T., Shirai, S., Okamoto, A., and Suyama, S., IEEE Trans. Electron Devices, 34, 321 (1987)

26. Li, C. C., Ikeda, H., Inoue, T., and Ko, P. K., IEDM Tech. Dig., 497 (1993)

27. Guan, X., Liu, X., and Han, R., Proc. 4th Int. Conf. Solid-State Integr. Circuit Technol., 604 (1995)

28. Ahmed, S. S., Kim, D. M., and Shichijo, H., IEEE Electron Device Lett., 6, 313 (1985)

29. Ono, K., Aoyama, T., Konishi, N., and Miyata, K., IEEE Trans. Electron Devices, 39, 792 (1992)

30. Fossum, J. G., and Conde, A. O., IEEE Trans. Electron Devices, 30, 933 (1983)

31. Farmakis, F. V., Brini, J., Kamarinos, G., Angelis, C. T., Dimitriadis, C. A., Miyasaka, M., and Ouisse, T., Solid State Electron., 44, 913 (2000)

32. Hatzopoulos, A. T., Tassis, D. H., Hastas, N. A., Dimitriadis, C. A., and Kamarinos, G., IEEE Transactions on Electron Devices, 52, 1727 (2005)

33. Fortunato, G. and Migliorato, P., Appl. Phys. Lett., 49, 1025 (1986)

34. ATLAS User's Manual: Silvaco International, Santa Clara, CA, 2007

35. Garcia-Cuenca, M. V., Morenza, J. L. and Codina, J. M., J. Phys. D: Appl. Phys., 20, 951 (1987)

36. Orton, W. and Powell, M. J., Rep. Prog. Phys., 43 (1980)

37. Orouji, A. A., and Kumar, M. J., IEEE Transactions on Device and Materials Reliability, 5 (2005)

38. Caughey, D.M., Thomas, R. E., Proceedings IEEE, 55, 2192 ( 1967)

39. Kim, S.-W., Lee, S. K., Kim, Y. D., and Kim S., Appl. Phys. Lett., 96, 262904 (2010)

40. Tipler, P. A. and Llewellyn, R. A., Modern Physics, 3rd Ed., W.H. Freeman, 1999

41. Szadkowski, A. J., Kalnitsky, A., Ma, K. B., Zukotynski, S., J. Appl. Phys., 53, 557 (1982)

42. Streetman, B. G., Banerjee, S. K., Solid State Electronic Devices, 6th Ed. Prentice Hall (2006)

43. Goodman, A. M., J. Appl. Phys., 35, 573 (1964)

44. Rakhshani, A. E., J. Phys.: Condens. Matter., 12, 4391 (2000)

45. Partain, L. D., J. Appl. Phys., 63, 1762 (1988)

46. Guerrieri, R., Ciampolini, P., Gnudi, A., Rudan, M., and Baccarani, G., IEEE Transactions on Electron Devices, 33, 1201 (1986)

47. Jagar, S., Wang, H., and Chan, M., IEEE Electron Device Lett., 22, 218 (2001)

48. Walker, P. M., Uno, S. and Mizuta, H., Jpn. J. Appl. Phys., 44, 8323 (2005)

49. Yang, H. G., Im, H. B., Journal of Materials Science, 21, 775 (1986)

50. Grovenor, C. R. M., J. Phys. C: Solid State Phys., 18, 40793119 (1985)

51. Wang, L., Fine, D., Basu, D., and Dodabalapur, A., J. Appl. Phys. 101(2007) 54515

52. Calvert, P., Chem. Mater. 13 (2001) 3299

53. Kol, S. H., Panl, H., Grigoropoulos, C. P., Luscombe, C. K., Frechet, J. M., and

Poulikakos, D., Nanotechnology, 18 (2007)345202 
54. Jackson, T. N., Lin, Y., Gundlach, D. J., and Klauk, H., IEEE Journal of Selected Topics in Quantum Electronics, 4 (1998)

55. Wondmagegn, W.T., Satyala, N.T., Pieper, R. J., Quevedo-Lopez, M. A., Gowrisanker, S., Alshareef, H.N., Stiegler, H.J., Gnade, B.E., J. Comput Electron 10, 144 (2011) 56. Flora Li, Arokia Nathan, Yiliang Wu, Beng S. Ong, Organic Thin Film Transistor Integration: A hybrid Approach, Wiley-VCH, March 2011

57. SmartSpice/UTMOST III Modeling Manual Volume 2

58. Zysset, C. Munzenrieder, N. ; Petti, L. ; Buthe, L. ; Salvatore, G.A. ; Troster, G., Electron Device Letters, IEEE_34, 11, (2013) 1394 - 1396

59. Yokota, T. Sekitani, T. ; Tokuhara, T. ; Zschieschang, U. ; Klauk, H. ; Tsung-Ching Huang ; Takamiya, M. ; Sakurai, T. ; Someya, T., Electron Devices Meeting (IEDM), 2011 IEEE International, 5-7 Dec. 2011 Page(s): 14.4.1 - 14.4.4

60. Maiellaro, G. Ragonese, E. ; Castorina, A. ; Jacob, S. ; Benwadih, M. ; Coppard, R. ; Cantatore, E. ; Palmisano, G, IEEE Trans. Circuits Syst. 2013, 60, 3117.

61. Sambandan, S., Electron Device Letters, IEEE 29, 8 (2008) 882 - 884

62. Daniele Raiteri, Eugenio Cantatore, Arthur van Roermund, Circuit Design on Plastic Foils (Analog Circuits and Signal Processing), Springer, Dec 3, 2014 


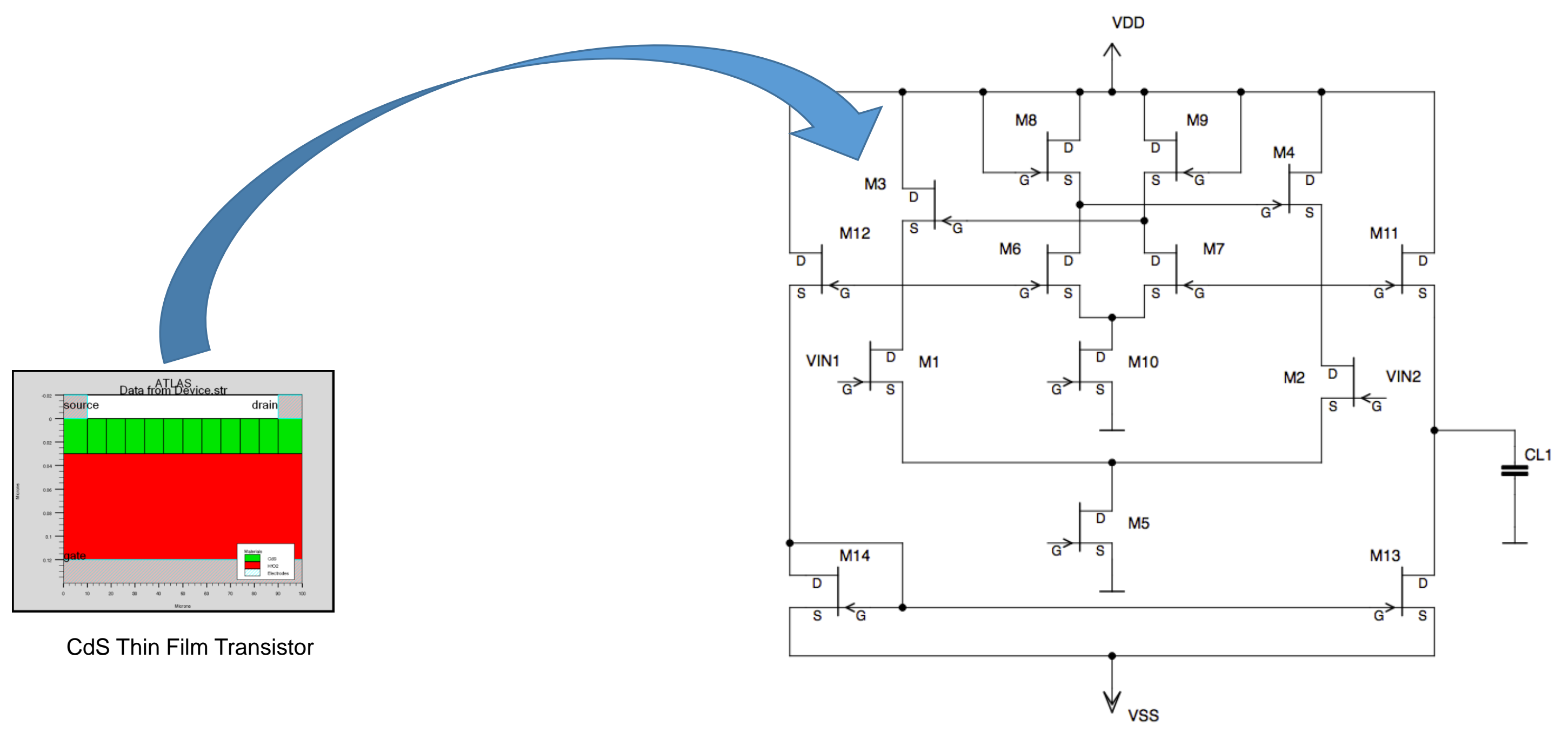

All n-type OPAPM 